\title{
Glucocorticoid receptor heterozygosity combined with lack of receptor auto-induction causes glucocorticoid resistance in Jurkat acute lymphoblastic leukemia cells
}

\author{
S Riml ${ }^{1}$, S Schmidt ${ }^{2}$, MJ Ausserlechner ${ }^{1}$, S Geley $^{1}$ and \\ R Kofler ${ }^{\star, 1,2}$ \\ 1 Division of Molecular Pathophysiology, Institute of Pathophysiology, University \\ of Innsbruck Medical School, Fritz-Pregl-Str. 3, A-6020 Innsbruck, Austria \\ 2 Tyrolean Cancer Research Institute at the University of Innsbruck, Innrain 66, \\ A-6020 Innsbruck, Austria \\ * Correspondence: Reinhard Kofler, M.D., Tyrolean Cancer Research Institute, \\ Innrain 66, A-6020 Innsbruck, Austria, Tel: 0043-512-57 04 85-11; \\ Fax: 0043-512-57 04 85-44, E-mail: reinhard.kofler@uibk.ac.at
}

Received 28.5.03; revised 19.11.03; accepted 10.12.03; published online 12.3.04 Edited by RA Knight

\begin{abstract}
Glucocorticoids (GC) induce apoptosis in malignant lymphoblasts, but the mechanism of this process as well as that of the clinically important GC resistance is unknown. We investigated GC resistance in Jurkat T-ALL cells in which ectopic GC receptor (GR) restores GC sensitivity, suggesting deficient GR expression. Jurkat cells expressed one wild-type and one mutated (R477H) GR allele. $\mathbf{G R}^{\mathrm{R} 477 \mathrm{H}}$ ligand-bindingdependent nuclear import, as revealed by live-cell microscopy of YFP-tagged GR, was unaffected. Transactivation and transrepression were markedly impaired; however, GR $^{\mathrm{R} 477 \mathrm{H}}$ did not act in a dominant-negative manner, that is, did not prevent cell death, when introduced into a GC-sensitive cell line by retroviral gene transfer. Contrary to another GR heterozygous, but GC-sensitive, T-ALL model (CCRF-CEM), Jurkats expressed lower basal GR levels and did not autoinduce their GR, as revealed by 'real-time' RT-PCR and immunoblotting. Absent GR auto-induction could not be restored by transgenic GR and, hence, was not caused by reduced basal GR levels. Thus, inactivation of one GR gene results in haploinsufficiency if associated with lack of GR auto-induction.
\end{abstract}

Cell Death and Differentiation (2004) 11, S65-S72.

doi:10.1038/s..cdd.4401413

Published online 12 March 2004

Keywords: lymphoblastic leukemia; glucocorticoid resistance; apoptosis; glucocorticoid receptor

Abbreviations: Dex, dexamethasone; GC, glucocorticoids; GFP, green fluorescent protein; GILZ, glucocorticoid-induced leuzin zipper; GR, glucocorticoid receptor; NLS, nuclear localization signal; T-ALL, acute T-cell lymphoblastic leukemia; TBP, TATA box-binding protein; YFP, yellow fluorescent protein.

\section{Introduction}

Glucocorticoids (GC) are an important element of essentially every therapeutic regimen for lymphoid malignancies. ${ }^{1,2}$ In childhood ALL treatment protocols, an introductory GC monotherapy is used to distinguish GC good responders with an overall favorable prognosis from GC nonresponders with a far worse outcome. ${ }^{3}$ In addition to its purpose as a prognostic factor, the introductory mono-therapy has therapeutic value since it dramatically reduces leukemic blasts in GC-sensitive patients within a few days. The remaining tumor burden is then attacked by different chemotherapeutics combined with GCs. Despite its obvious importance, the molecular mechanisms underlying GC-induced apoptosis and, clinically even more relevant, GC resistance remain unresolved (reviewed in Kofler et al. ${ }^{4}$ ).

GC act through their cognate receptor (GR), a ligandactivated transcription factor of the Zn-finger type. ${ }^{5,6}$ Upon ligand binding, the activated GR translocates into the nucleus, where it acts as a sequence-specific transcription factor to induce or repress the expression of a large number of target genes. ${ }^{7-10}$ Alternatively, the GR can influence gene expression without directly interacting with DNA through proteinprotein interaction with a number of transcription factors and co-factors. ${ }^{11}$ The subsequent alterations in gene expression are considered responsible for $\mathrm{GC}$ induction of cell death and cell cycle arrest, another important antileukemic GC effect. While repression of cyclin D3 and c-myc has been identified as essential for GC-induced cell cycle arrest in CCRF-CEM cells, ${ }^{12}$ the critical target genes responsible for GC-induced apoptosis are still not well defined. Similarly, mechanisms causing resistance to GC-induced apoptosis are poorly understood.

Although numerous possibilities exist, the most convincing evidence has been provided for resistance mechanisms acting at the level of the GR (reviewed in Kofler et al. ${ }^{4}$ ). This might be explained by the fact that selection for $\mathrm{GC}$ resistance requires neutralization of both apoptotic and antiproliferative GC effects, which apparently occur through largely independent pathways. ${ }^{12}$ Thus, loss-of-function mutations in the GR gene have been reported in GC-resistant ALL cell lines. ${ }^{13-16}$ Moreover, evidence has been provided that GC-induced apoptosis is critically dependent upon GR auto-induction, ${ }^{4,17,18}$ suggesting that sufficient GR expression must be maintained during a critical period of GC exposure to precipitate cell death. ${ }^{19}$ More specifically, CCRF-CEM cells, perhaps the best studied model for GC-induced apoptosis in human ALL, carry a GR gene mutation (L753F) on one allele that has already occurred in vivo ${ }^{20}$ and markedly impairs ligand binding. ${ }^{21}$ GC-resistant CCRF-CEM derivatives (mostly established by selection in GC-containing media) 
have either acquired loss-of-function mutations in the GR gene of the second allele, ${ }^{13-16}$ have reduced basal GR levels $^{22}$ and/or fail to sufficiently auto-induce their functional GR gene upon GC exposure. ${ }^{4}$

To gain further insights into the mechanism of $\mathrm{GC}$ resistance in leukemic cells, we investigated a different GCresistant T-ALL model, that is, the human T-ALL cell line Jurkat which is widely used in apoptosis research and has been exploited as a model for the molecular analysis of GR mutants. Helmberg et al. ${ }^{23}$ have shown that GR overexpression in Jurkat cells is sufficient to restore GC sensitivity. This finding suggested that Jurkat cells owe their GC-resistant status to qualitative (GR mutations) or quantitative defective GR expression, but molecular data addressing this possibility have not been provided. In this study, we show that Jurkat cells harbor a function-impairing point mutation $(\mathrm{R} 477 \mathrm{H})$ in one of their GR alleles that, along with a failure to auto-induce the functional GR allele, might cause $\mathrm{GC}$ resistance in this ALL cell line.

\section{Results and discussion}

\section{Jurkat cells carry one wild-type and one mutated (R477H) GR allele}

Previous studies revealed that overexpression of transgenic GR suffices to restore GC responsiveness in Jurkat T-ALL cells, ${ }^{23}$ suggesting that $\mathrm{GC}$ resistance in this cell line occurs at the level of the GR. To address this possibility further, we amplified Jurkat GR cDNA, cloned it into pEF $\Delta T$ and sequenced a number of independently derived clones. Excluding occasional sequence alterations introduced by the Taq polymerase, two types of clones could be distinguished (Figure 1). One of these clones corresponded to the human GR wild-type sequence, ${ }^{24}$ differing only in a known silent polymorphism in codon 766 (AAT $\rightarrow$ AAC),${ }^{25}$ the other differed by a missense mutation in codon 477 (CGC $\rightarrow C A C)$,

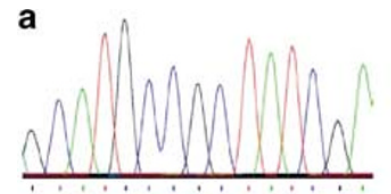

GC A T G C C G C TA T C GA

C

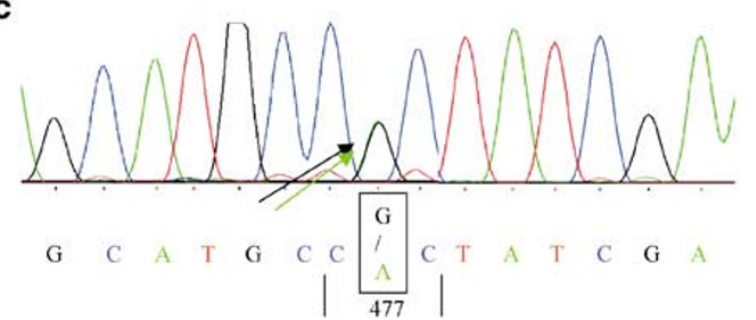

Figure 1 The GR gene of Jurkat cells contains a point mutation in codon 477 . Jurkat GR cDNA was PCR-amplified, subcloned into an expression vector and sequenced. The region surrounding codon 477 from cDNAs corresponding to the wild-type (a) and the mutated alleles (b) is shown. GR Exon 4 was PCR-amplified from genomic Jurkat DNA and sequenced. Arrows highlight the heterozygous position $\mathrm{G} / \mathrm{A}$ in codon 477 (c) leading to an arginine $(R) \rightarrow$ histidine $(H)$ exchange. To verify the presence of this productive mutation, we amplified genomic DNA encompassing exon 4 and subjected it to bulk sequencing. As can be seen in Figure 1, Jurkat cells harbor a heterozygous $\mathrm{G} \rightarrow \mathrm{A}$ transition at the second position of codon 477 in exon 4.

Thus, Jurkat cells carry one wild-type and one mutated GR allele. Since heterozygosity at the GR locus is also present in GC-sensitive cell lines, ${ }^{16}$ this mutation would fully explain the GC-resistant phenotype only if it abrogated the function of the affected GR allele and exerted a dominant-negative effect on the remaining wild-type GR allele. To address these questions, we investigated the possible effects of the $\mathrm{R} 477 \mathrm{H}$ mutation on GR function.

\section{$\mathrm{GR}^{\mathrm{R} 477 \mathrm{H}}$ mutation impairs transactivation and transrepression, but not ligand binding or translocation, and is not dominant negative}

Interestingly, the $\mathrm{GR}^{\mathrm{R} 477 \mathrm{H}}$ mutation was previously observed in a patient with primary cortisol resistance (in combination with a GR ${ }^{\mathrm{wt}}$ allele) ${ }^{26}$ and in a GC-resistant subclone of the mouse S49 thymoma line (where R477 corresponds to R484), in association with the mouse $\mathrm{GR}^{\mathrm{E546G}}$ mutation on the second allele. ${ }^{27}$ The mutation did not detectably affect ligand binding in either system nor change the GR affinity (tested in the human system only). Both groups reported that the mutation abrogated the ability of the GR to transactivate a GRE-containing reporter construct. In the mouse system, this was associated with a reduced ability of the ligand-activated GR to translocate into the nucleus, whereas in the human system deficient DNA binding (deduced from 3D structure predictions) was made responsible. Whether $\mathrm{R} 477 \mathrm{H}$ affects transrepression or might act in a dominant-negative fashion has not been investigated.

To clarify whether the human mutation affects nuclear import similar to findings in mice, ${ }^{27}$ we transfected Cos-7 cells with expression plasmids for wild-type and mutated GR, along with an expression vector for green fluorescent protein (GFP), incubated them in the presence or absence of dexamethasone for $3 \mathrm{~h}$ and determined GR localization by indirect immunofluorescence (Figure 2a). In the absence of hormone, both receptors were mainly cytoplasmic, while addition of GC caused complete translocation of the receptor into the nucleus. Thus, $\mathrm{R} 477 \mathrm{H}$ did not detectably block liganddependent nuclear GR import. Since this end-point assay might have not detected defects in nuclear import kinetics, we applied live-cell microscopy to microinjected U2OS cells expressing $\mathrm{GR}^{\mathrm{R} 477 \mathrm{H}}$ or $\mathrm{GR}^{\mathrm{wt}}$ tagged with yellow fluorescent protein (YFP). Both GR-YFP constructs were cytoplasmic in unstimulated U2OS cells and rapidly (maximum after $30 \mathrm{~min}$ ) translocated into the nucleus after dexamethasone addition (Figure $2 \mathrm{~b}$ ). Hence, the $\mathrm{R} 477 \mathrm{H}$ mutation did not affect the overall GR translocation or its kinetics.

To further investigate the ability of $\mathrm{GR}^{\mathrm{R} 477 \mathrm{H}}$ to transactivate gene expression, we compared the mutation with the $\mathrm{GR}^{\mathrm{wt}}$ in a renilla luciferase-normalized Cos-7 transfection system. In agreement with the above-mentioned reports, ${ }^{26,27}$ transfection of $\mathrm{GR}^{\mathrm{wt}}$ resulted in dose-dependent induction of 


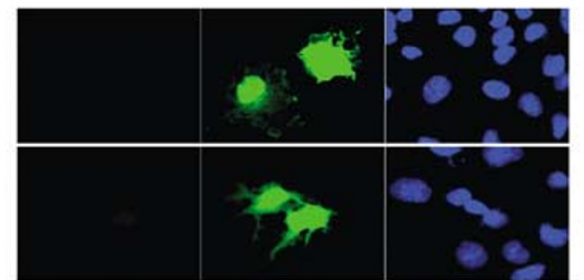

$\mathrm{GR}^{\mathrm{wt}}$

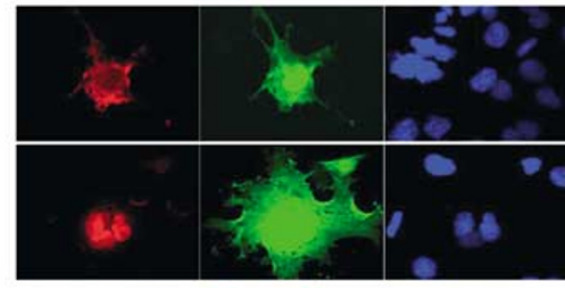

$+$

$\mathrm{GR}^{\mathrm{R} 477 \mathrm{H}}$
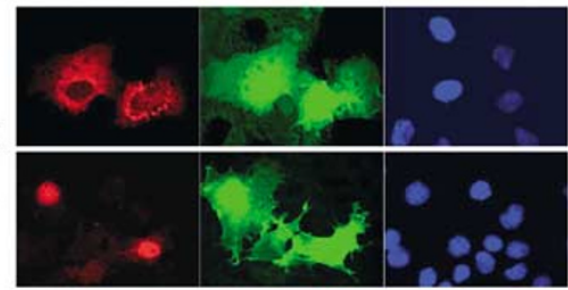

$-$

$+$

b

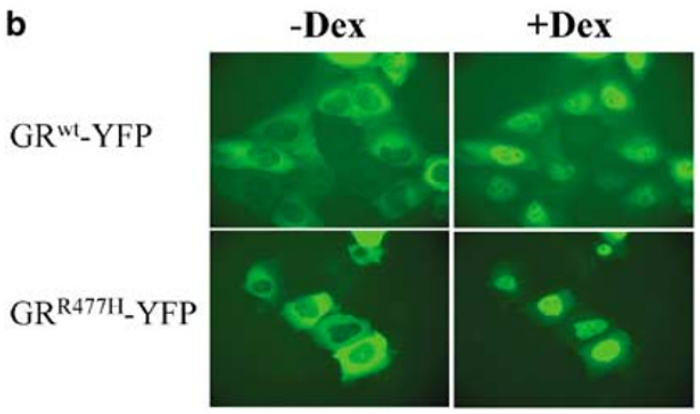

+ Dex

Figure 2 Effect of R477H on hormone-dependant nuclear GR import. (a) Fluorescence detection of nuclear translocation: Cos-7 cells were transiently transfected with empty plasmids (0) and plasmids pEF- $\Delta T-h \mathrm{GR}^{\mathrm{wt}}\left(\mathrm{GR}^{\mathrm{wt}}\right)$ and pEF- $\Delta T-h R^{R 477 H}\left(G R^{R 477 H}\right.$ ) along with a plasmid encoding GFP as a transfection control. Subsequently, the cells were cultured in the absence $(-)$ or presence $(+)$ of $10^{-7} \mathrm{M}$ dexamethasone (dex) for $3 \mathrm{~h}$, fixed and stained with Hoechst 33342 (for nuclear staining) and an anti-human GR antibody, followed by a TRITC-labeled secondary antibody. Fluorescence was detected by confocal microscopy with a section thickness of $1.5 \mu \mathrm{m}$. (b) Fluorescence live-cell imaging: U2OS cells were seeded on glass-bottom wells, micro-injected with either pEF-pldelHIII-hGR ${ }^{\text {wt }}$-YFP or pEF-pldelHIII-hGR ${ }^{\text {R477H-YFP }}$ and fluorescence pictures taken prior to and at several time points after exposure to $10^{-7} \mathrm{M}$ dexamethasone. The pictures taken at $0 \mathrm{~h}$ (-Dex) and after $30 \mathrm{~min}$ (+ Dex) are shown

luciferase activity from an MMTV-luciferase reporter construct, while $\mathrm{GR}^{\mathrm{R} 477 \mathrm{H}}$ almost completely failed to transactivate the reporter gene (Figure 3a). Similarly, when tested on a TPA-induced, collagenase promoter-driven reporter construct to assess transrepression ability, $\mathrm{GR}^{\mathrm{R} 477 \mathrm{H}}$ did not repress luciferase (Figure $3 b$ ). To the contrary, there was even a slight increase in luciferase expression suggesting that the mutant might paradoxically induce, rather than repress, this (and perhaps other) promoter(s), as has been reported for the rat K461 A mutation that is located next to the fourth cystein in the first $\mathrm{Zn}$ finger. ${ }^{28,29}$ Thus, the $\mathrm{R} 477 \mathrm{H}$ mutation markedly

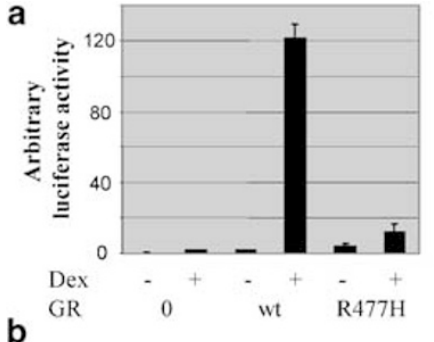

d

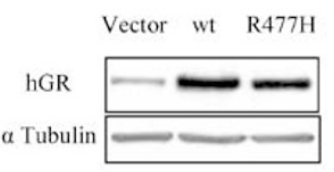

b
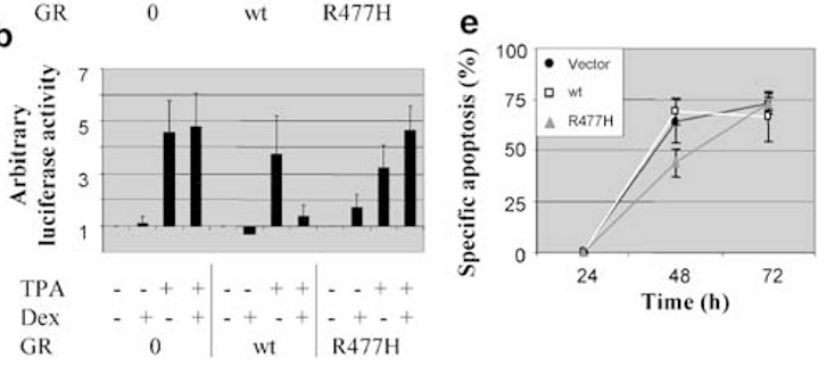

c

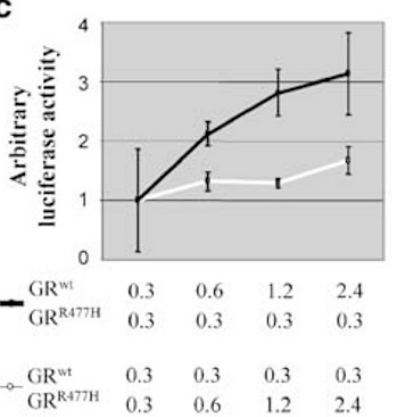

Figure 3 Effect of R477H on GR transactivation and transrepression. (a) Transactivation potential: Cos-7 cells were transiently transfected with pMMTVGL3-Luciferase, pSV40-Renilla-Luciferase and equal amounts of an empty control plasmid (0), pEF $\Delta \mathrm{T}-\mathrm{hGR}^{\mathrm{wt}}$ (wt), or pEF $\Delta \mathrm{T}-\mathrm{hGR}^{\mathrm{R} 477 \mathrm{H}}$ (R477H) and cultured in the absence $(-)$ or presence $(+)$ of $10^{-7} \mathrm{M}$ dexamethasone (Dex) for $24 \mathrm{~h}$. Equal amounts of protein were used for luciferase assays. The means \pm S.D. of luciferase activity normalized against co-expressed constitutive Renilla luciferase levels of three independent experiments performed in triplicate are shown. (b) Transrepression potential: Cos-7 cells were transiently transfected with $\mathrm{pCOl}$-Luc and equal amounts of an empty control plasmid (0), pEF $\Delta T$-hGR ${ }^{\text {wt }}$ (wt) or pEF $\Delta T-\mathrm{TGR}^{\mathrm{R} 477 \mathrm{H}}$ (R477H). After overnight culture, the cells were incubated with $10^{-7} \mathrm{M}$ dexamethasone ( + Dex) or solvent $(-)$ for $1 \mathrm{~h}$, followed by the addition of $50 \mathrm{ng} / \mathrm{ml}$ TPA and $4 \mu \mathrm{m}$ ionomycin (to induce $\mathrm{pCol}-$ Luc) for another $8 \mathrm{~h}$. Equal amounts of protein were used for luciferase assays. The means \pm S.D. of luciferase activity of three independent experiments are shown. (c-e) Analysis of dominant-negative effects: (c) Cos-7 cells were transiently transfected with $0.3 \mathrm{ng}$ of $\mathrm{pEF} \Delta \mathrm{T}$-hGR ${ }^{\mathrm{wt}}(\mathrm{Wt}$ ) and increasing amounts of $p E F \Delta T-h G R^{R 477 H}(R 477 H)$ or $0.3 n g$ of $p E F \Delta T-h G R^{R 477 H}$ and increasing amounts of $\mathrm{pEF} \Delta \mathrm{T}-\mathrm{hGR}^{\mathrm{wt}}$ as indicated. MMTV luciferase assays were performed as described above. The mean \pm S.D. of a representative experiment performed in triplicate is shown. (d-e) GC-sensitive CEM-C7H2 cells were infected with retroviruses coding for $\mathrm{GR}^{\mathrm{wt}}(\mathrm{wt}), \mathrm{GR}^{\mathrm{R} 47 \mathrm{H}}(\mathrm{R} 477 \mathrm{H})$ or the vector control. Protein extracts from all cell lines were subjected to immunoblotting analyses with antibodies specific for human GR (hGR) and $\alpha$-tubulin as a loading control (d). GC-induced apoptosis was determined in all cell lines after treatment with $10^{-7} \mathrm{M}$ dexamethasone for the time indicated (e). Specific apoptosis represents the percentage of sub-G1 nuclei in hormone-treated cells after subtraction of apoptotic nuclei in vehicle-treated controls (around 4\%). The mean \pm S.D. of three independent experiments is shown

impaired the ability of GR to transactivate and to transrepress gene expression.

To examine whether the mutated GR acts as a dominantnegative mutant by inhibiting the transactivation potential of the wild-type GR, we first co-transfected Cos-7 cells with a 
defined amount of wild-type GR and increasing levels of the mutated GR (and vice versa), and measured the induction of luciferase from an MMTV-driven luciferase construct. Figure $3 \mathrm{c}$ shows that co-expression of increasing levels of $\mathrm{GR}^{\mathrm{R} 477 \mathrm{H}}$ did not interfere with the ability of the wild-type receptor to induce the MMTV-luciferase reporter, suggesting that $\mathrm{R} 477 \mathrm{H}$ might not be dominant negative. To address this question in more detail, we transduced GC-sensitive CCRF$\mathrm{CEM}-\mathrm{C} 7 \mathrm{H} 2$ cells $^{14}$ with recombinant retroviruses allowing constitutive expression of $\mathrm{GR}^{\mathrm{R} 477 \mathrm{H}}$. As controls, retroviruses expressing $\mathrm{GR}^{\mathrm{wt}}$ or just the selection marker were used. Although $\mathrm{GR}^{\mathrm{R} 477 \mathrm{H}}$ was expressed at considerably higher levels than the endogenous GR (Figure 3d), the cells transduced with the mutant GR underwent GC-induced apoptosis to the same degree and with similar kinetics as those transduced with $\mathrm{GR}^{\mathrm{wt}}$ or 'empty' retrovirus (Figure $3 \mathrm{e}$ ). This clearly showed that $\mathrm{GR}^{\mathrm{R} 477 \mathrm{H}}$ does not act in a dominantnegative manner, which is in agreement with the suggestion derived from molecular dynamic studies that R496 (the corresponding residue in rat GR) might be essential for dimerization and DNA binding. ${ }^{30}$ Hence, the mutation alone did not sufficiently explain the GC-resistant phenotype of Jurkat T-ALL cells.

\section{GC-resistant Jurkat and CEM-C1 cells express less basal GR than GC-sensitive CEM-C7H2 cells and do not auto-induce their GR}

In other GR heterozygous T-ALL systems, that is, CCRFCEM cells with the L753F mutation that impairs ligand binding, ${ }^{21}$ basal GR expression and/or auto-induction of the wild-type allele have been implicated in GC sensitivity. ${ }^{4,22}$ To compare these parameters in the two human T-ALL systems, we first exploited 'real time' RT-PCR to quantitate GR expression prior to, and $12 \mathrm{~h}$ after, GC exposure at the mRNA level in GC-sensitive CCRF-CEM-C7H2 (phenotype GR ${ }^{\mathrm{L} 753 \mathrm{~F} / \mathrm{wt}}$ ), ${ }^{16}$ GC-resistant CEM-C1 (same phenotype $\mathrm{GR}^{\mathrm{L753F} / \mathrm{wt}}$ ) $^{22}$ and Jurkat (phenotype GR ${ }^{\mathrm{R} 477 \mathrm{H} / \mathrm{wt}}$ ) T-ALL cells. GC-resistant CEM-C7R $5^{13}$ cells that are homo- or hemizygous for $\mathrm{GR}^{\mathrm{L753F}}$ were included as control without a wild-type GR gene. As shown in Figure 4a, Jurkat cells expressed the lowest basal levels of GR, CEM-C7R5 and CEM-C1 somewhat higher, and $\mathrm{CEM}-\mathrm{C} 7 \mathrm{H} 2$ the highest levels. Perhaps more importantly, only GC-sensitive CEM-C7H2 cells significantly auto-induced their GR gene upon GC exposure, thereby further increasing their GR levels two- to four-fold (Figure 4a). Induction of GILZ, a known GR target gene ${ }^{31}$ included for control purposes, correlated reasonably well with GR levels and the extent of GR auto-induction in CEM-C7H2, CEM-C1 and Jurkat cells. Why Jurkat cells slightly induced GILZ mRNA expression but not that of GR is unclear; however, it might reflect promoterspecific differences (e.g. the presence of GREs, differences in expression of transcription factors acting on these promoters, etc.). As expected, CEM-C7R5 cells, which only express L753F mutated GR, failed to induce GILZ (Figure 4b).

To determine whether the effects seen on the mRNA level correlated with GR protein expression, whole cell extracts from Jurkat cells were compared with those from $\mathrm{CEM}-\mathrm{C} 7 \mathrm{H} 2$, CEM-C1 and CEM-C7R5 in immunoblotting assays. Basal
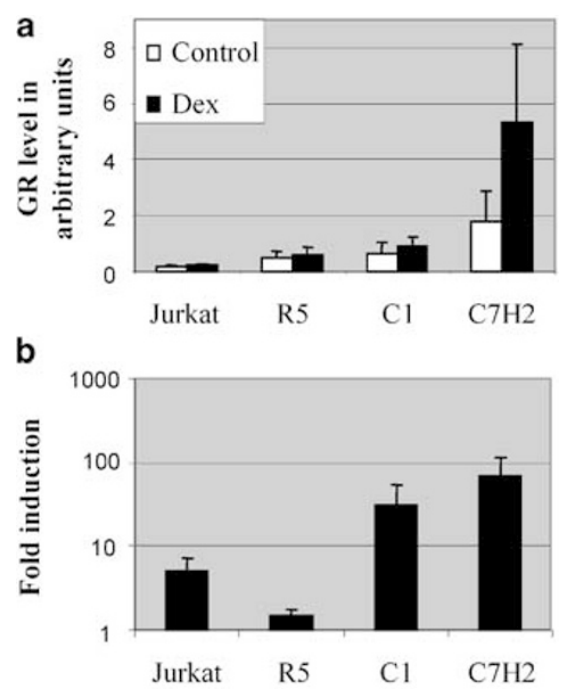

Figure 4 Real-time PCR analyses of GR basal levels, GR auto-induction and GC induction of GILZ. RNA from GC-sensitive CEM-C7H2 and GC-resistant Jurkat, CEM-C1 and CEM-C7R5 cells cultured for $12 \mathrm{~h}$ in the absence or presence of $10^{-7} \mathrm{M}$ dexamethasone were subjected to 'real-time'RT-PCR with primers for GR, GILZ and TBP as a control. The GR levels normalized to TBP (a, means \pm S.D. of three independent experiments performed in triplicate) are shown and fold induction of GILZ levels normalized to TBP (b, means \pm S.D. of 2-3 independent experiments performed in triplicate)

GR protein expression in all the three GC-resistant cells was approximately half that of GC-sensitive $\mathrm{CEM}-\mathrm{C} 7 \mathrm{H} 2$ cells (Figure 5a). To quantitate the fraction of GR capable of binding its ligand in these cell lines, we performed whole-cell radioligand binding assays using ${ }^{3} \mathrm{H}$-triamcinolone (Figure 5b). Specific binding roughly corresponded to GR protein expression, that is, GC-resistant Jurkat and CEM-C1 bound similar levels of ${ }^{3} \mathrm{H}$-triamcinolone, but approximately 2.5-fold less than GC-sensitive CEM-C7H2 cells. As expected, CEM-C7R5 cells, which only express ligand-bindingdeficient $\mathrm{GR}^{\mathrm{L} 753 \mathrm{~F}}$, did not bind GC. Finally, we investigated GR auto-induction in our cell panel on the protein level. As shown above on the mRNA level, treatment of cells for $12 \mathrm{~h}$ with $10^{-7} \mathrm{M}$ dexamethasone caused $\mathrm{GR}$ upregulation in the sensitive cell line $\mathrm{C} 7 \mathrm{H} 2$, but did not detectably change GR levels in the three GC-resistant cell lines (Figure $5 \mathrm{c}$ ).

The observation that GR auto-inducing CEM-C7H2 cells exhibited higher basal GR levels than non-auto-inducing CEM-C1 or Jurkat cells raised the possibility that the failure to induce GR expression might be due to low basal GR levels. To address this question, we used Jurkat ${ }^{23}$ and $C E M-C 1^{22}$ derivatives stably transfected with rat GR. Although these cells reportedly express high levels of transgenic GR (not seen in Figure $5 d$ because the antibody to human GR does not recognize rat $G R$ ), they failed to induce their endogenous GR after GC treatment (Figure $5 d$ ), suggesting that basal GR levels might not determine whether such cells upregulate their GR upon GC exposure.

In conclusion, we have shown that the widely used T-ALL cell line Jurkat expresses one functional and one mutated GR allele $\left(\mathrm{GR}^{\mathrm{R} 477 \mathrm{H}}\right)$. This, combined with the observation that the CCRF-CEM-C1 human T-ALL cell line also carries one wildtype and one inactive allele, ${ }^{22}$ suggested haploinsufficiency at 


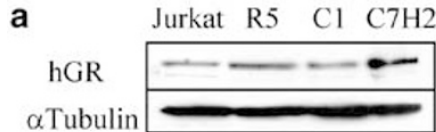

b

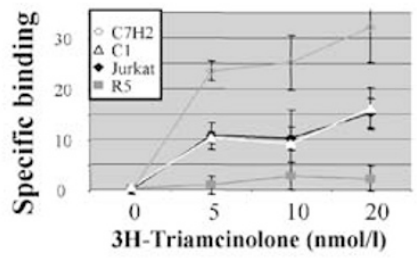

C

$\begin{array}{llll}\text { Jurkat } & \mathrm{R} 5 & \mathrm{Cl} & \mathrm{C} 7 \mathrm{H} 2\end{array}$
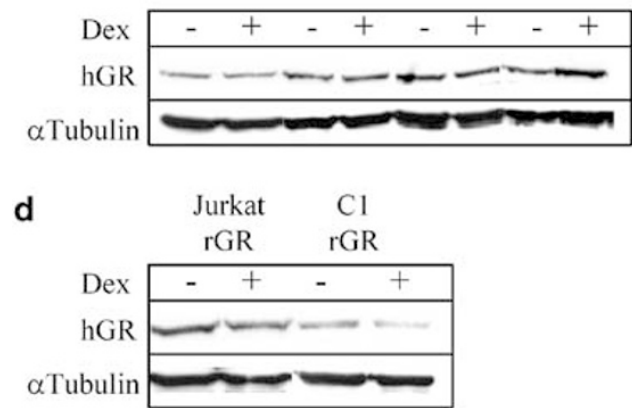

Figure 5 Determination of GR basal levels and GR auto-induction. (a) Basal GR protein expression: protein extracts from GC-resistant Jurkat, CEM-C7R5 (R5), CEM-C1 (C1) and GC-sensitive CEM-C7H2 (C7H2) were subjected to Western blotting analyses with antibodies specific for human GR (hGR) and $\alpha$ tubulin as a loading control. (b) GR ligand binding: GC-resistant Jurkat, CEM-R5 and $\mathrm{CEM}-\mathrm{C} 1$, and $\mathrm{GC}$-sensitive $\mathrm{CEM}-\mathrm{C} 7 \mathrm{H} 2$ cells were subjected to whole-cell radioligand-binding assay, as described in Materials and methods. The means of specifically bound radioactivity from an assay performed in triplicate are shown. (c) GR auto-induction: Protein extracts from GC-resistant Jurkat, CEM-C7R5 (R5) and CEM-C1 (C1), and GC-sensitive CEM-C7H2 (C7H2) cells cultured for $12 \mathrm{~h}$ in the absence $(-)$ or presence $(+)$ of $10^{-7} \mathrm{M}$ dexamethasone (Dex) were subjected to Western blotting analyses with antibodies specific for human GR (hGR) and $\alpha$-tubulin as a loading control. (d) GR auto-induction in rat GR expressing cell lines: Jurkat ${ }^{23}$ and $\mathrm{CEM}-\mathrm{C}^{22}$ cells transfected with rat GR (Jurkat-rGR and CEM-rGR, respectively) were treated and subjected to Western blotting analyses as outlined above. Increased levels of rat GR (not detected on this assay by the human GR specific antibody used here) did not restore autoinduction of the endogenous (human) GR

the GR locus as a possible explanation for the frequent occurrence of GC resistance in acute leukemia. However, other CCRF-CEM cell lines, like CEM-C7H2, have the same genotype as CEM-C1 (i.e. are heterozygous at the GR locus), yet are fully GC-sensitive. GC-sensitive CCRF-CEM lines showed the phenomenon of GR auto-induction, whereas CEM-C1 and Jurkats did not. In elegant experiments, Jeff Harmon's group showed that GC sensitivity is critically dependent upon GR induction (in this case by tetracyclineinduced expression of transgenic GR) and not upon slightly elevated basal GR levels in GC-sensitive versus GC-resistant CCRF-CEM clones. ${ }^{18}$ We show here that increased basal GR levels (by transgenic rat GR) do not restore GR autoinduction, indicating other mechanisms for the absence of GR auto-induction. Taken together, the combined findings in the two childhood ALL models suggested that GR heterozygosity causes GC resistance only if combined with a failure to auto-induce the wild-type GR allele.

\section{Materials and Methods}

\section{Cell lines and cell culture}

Jurkat T-ALL cells and Jurkat cells expressing transgenic ratGR ${ }^{\text {wt }}$ (JurkatratGR ${ }^{\text {wt }}$ ) were kindly provided by Arno Helmberg. ${ }^{23}$ GC-sensitive CCRFCEM-C7H $2^{14}$ and GC-resistant CCRF-CEM-C $1,{ }^{32}$ CEM-C1 expressing transgenic ratGR ${ }^{\mathrm{wt}}(\mathrm{CEM}-\mathrm{C} 1-4 \mathrm{G} 4)^{22}$ and $\mathrm{CEM}-\mathrm{C} 7 \mathrm{R} 5^{13}$ cells were described previously. Cos-7 monkey kidney and U2OS human osteosarcoma cells were derived from ATCC (Manassas, VA, USA). All cells used were PCR-tested for, and free of, mycoplasma. Their authenticity was verified by DNA finger-printing using 16 short-tandem repeats and comparison with previously published short-tandem repeat profiling. $^{33}$ Suspension cells were grown in RPMI 1640 (Bio Whitaker, Rockland, ME, USA), adherent cells in DMEM (Sigma, Vienna, Austria) at $37^{\circ} \mathrm{C}, 5 \%$ carbon-dioxide and saturated humidity. The media were supplemented with $10 \%$ fetal calf serum (Sigma), $100 \mathrm{U} / \mathrm{ml}$ penicillin, $100 \mu \mathrm{g} / \mathrm{ml}$ streptomycin and $2 \mathrm{~mm}$ L-glutamine (GibcoBRL, Paisley, UK).

\section{cDNA cloning and DNA sequencing}

Total RNA from Jurkat cells was isolated using Tri-Reagent ${ }^{\mathrm{TM}}$ (MRC, Cincinnati, OH, USA), and mRNA purified using Oligotex ${ }^{\mathrm{TM}}$ mRNA Kit (Qiagen, Valencia, CA, USA). cDNA was synthesized using Superscript ${ }^{\text {TM }}$ II reverse transcriptase (Invitrogen, Carlsbad, CA, USA) and oligo-dT Primers (Promega, Madison, WI, USA). The GR coding sequence was amplified with 25 PCR cycles using 2 units Taq DNA polymerase, $1.5 \mathrm{~mm}$ $\mathrm{MgCl}_{2}, 20 \mathrm{nM}$ of each primer (5'-TATACAATTGCCACCATGGACTCCAAAGAATCATTAAC-3' , and 5'-TATATCTAGACCATGGCCTTTTGATGAAACAGAAGTTTTTTG-3') and $200 \mathrm{~nm}$ of each nucleotide, and subjected to bulk sequencing (MWG-Biotech, Ebersberg, Germany). In addition, the amplified CDNA was inserted into an elongation factor $1 \alpha$ driven expression vector ( $p E F-\Delta T$, manuscript in preparation) generating plasmids $p E F-\Delta T-h R^{w t}$ and $p E F-\Delta T-h R^{R 477 H}$, respectively. Clones corresponding to the two $\mathrm{GR}$ alleles were distinguished by an Fnu4HI site, deleted in the R477H carrying GR allele. To rule out sequence alterations introduced by Taq DNA polymerase, several clones of each allele were sequenced. For each allele, a clone free of Taq DNA polymerase errors was selected for further functional analysis. To verify alterations in the cDNA sequence, genomic sequencing was performed using PCRamplified genomic DNA.

\section{Immunoblotting}

Washed cell pellets $\left(2.5 \times 10^{5}\right.$ cells/lane) were lysed in a buffer containing $12.5 \%$ Tris, $20 \%$ glycerol, $0.5 \mathrm{M} \mathrm{NaCl}, 40 \mathrm{~g} / \mathrm{SDS}$, and $0.5 \mathrm{~g} / \mathrm{l}$ bromphenol blue. After the addition of $10 \% 2-\beta$-mercaptoethanol, the lysates were exposed to ultrasound and boiled for $5 \mathrm{~min}$. Proteins were resolved on $10 \%$ acrylamide-gels and transferred to nitrocellulose. GR was detected by the human specific antibody E-20 (Santa Cruz, CA, USA; SC-1003), $\alpha$ tubulin as a loading control by the monoclonal antibody TAT1 (kindly provided by Julian Gannon). Signals were visualized using the $\mathrm{ECL}^{\mathrm{TM}}$ Western Blot Detection System (Amersham Pharmacia, Buckinghamshire, UK).

\section{'Real-time' RT-PCR}

Total RNA was prepared using TRI-reagent (MRC, Cincinnati, OH, USA) according to the manufacturer's protocol. RNA concentrations and quality were determined by measuring $O D$ at 260 and $280 \mathrm{~nm}$ and agarose gel 
electrophoresis. In all, $500 \mathrm{ng}$ total RNA was reverse transcribed in $25 \mu \mathrm{l}$ containing $250 \mathrm{ng}$ hexamer primers (MWG, Ebersberg, Germany) and 1 unit Superscript II (Invitrogen, Carlsbad, CA, USA). For design of primers and probes, the Primer-Express software (Applied Biosystems, Foster City, CA, USA) was applied. The primer and probe sequences were:

GR forward primer: GAACTTCCCTGGTCGAACAGTT (500 nM), GR reverse primer: GAGCTGGATGGAGGAGAGCTT (700nm), GR detection probe: TGGCTATTCAAGCCCCAGCATGAGA (5'-6FAM, 3'-TAMRA, $200 \mathrm{~nm}$ ),

TBP forward primer: GCCCGAAACGCCGAATA (700 nM), TBP reverse primer: CGTGGCTCTCTTATCCTCATGAT (700 nM), TBP detection probe: ATCCCAAGCGGTTTGCTGCGGT (5'-6FAM, $3^{\prime}$-Dabcyl, $200 \mathrm{~nm}$ ),

GILZ forward primer: CTTCTCTTCTCTGCTTGGAGGG (500 nM), GILZ reverse primer: CGATCTTGTTGTCTATGGCCAC (700 nM), GILZ detection probe: CTGGACAACAGTGCCTCCGGAGC (5'-6FAM, 3'-Dabcyl, $250 \mathrm{~nm}$ ).

For amplification, SureStart-Taq-Polymerase from Stratagene qPCR brilliant Core Kit (Stratagene, La Jolla, CA, USA) was used in a $2.5 \mathrm{~mm}$ $\mathrm{MgCl}_{2}$ containing the reaction mix supplemented with primers and probe for the corresponding target (final concentrations given above in parentheses). All reactions were run in triplicate in an i-cycler real-time PCR instrument (Bio-Rad, Hercules, CA, USA). Data analysis was performed using i-cycler-IQ software Version 3.0.

\section{Immunofluorescence}

Cos-7 cells were grown on glass coverslips, transiently transfected with GR constructs and pCS2-Venus (expressing GFP) ${ }^{34}$ as transfection control using Superfect ${ }^{\mathrm{TM}}$ Transfection Reagent (Qiagen, Valencia, CA, USA) according to the manufacturer's instructions and fixed using a paraformaldehyde fixation standard protocol. Paraformaldehyde was inactivated by glycin and cells were permeabilized by $0.1 \%$ Triton X-100. Human GR was detected by E-20 and visualized by a TRITC-labeled second antibody (Dako, Glostrup, Denmark; R156). Nuclei were stained with $1 \mu \mathrm{g} / \mathrm{ml}$ Hoechst 33342. Cells were embedded with Mowiol and fluorescence was detected with confocal microsopy.

\section{GR-YFP fluorescence live-cell imaging}

pEFpldelHIII-YFP was constructed by cloning an Ncol-Xbal digested PCR fragment encoding YFP5 ${ }^{35}$ into a pEFpl2-derived plasmid in which the Hindll site was deleted by Hindll restriction digest, filling in and religation to generate a YFP expression plasmid suitable for constructing $\mathrm{N}$ - and $\mathrm{C}$ terminal YFP fusion proteins. $h \mathrm{hR}^{\mathrm{wt}}$ and $\mathrm{hGR}^{\mathrm{R} 477 \mathrm{H}} \mathrm{cDNAs}$ were released from $p E F \Delta T$-hGR by $N c o l$ digestion and inserted into pEF-pldelHIII-YFP after linearization with $\mathrm{Ncol}$ and dephosphorylation, generating plasmids pEF-pldelHIII-hGR ${ }^{\text {wt }}$-YFP and pEF-pldeHIII-hGR ${ }^{R 47 H_{-}}$-YFP, respectively. Correct insert orientation was verified by restriction enzyme analyses. The resulting vectors code for an elongation factor $1 \alpha$-driven GR-YFP fusion protein with YFP at the carboxy terminus. Constructs were microinjected into U2OS cells using a FemtoJet microinjector equipped with an InjectMan micromanipulator (Eppendorf, Wessling-Berzdorf, Germany) and hormone-dependent nuclear transfer visualized by an Axiovert $200 \mathrm{M}$ (Zeiss, Jena, Germany) equipped with a Coolsnapfx CCD camera (Roper Scientific, Ottobrunn, Germany) driven by Metamorph software (Universal Imaging, Downingtown, PA, USA).

\section{MMTV-Iuciferase assay}

Cos-7 cells were transiently transfected with pMMTV-GL3-Luciferase, ${ }^{36}$ pSV40-Renilla-Luciferase (Promega, Madison, WI, USA) and equal amounts of pEF- $\Delta T-h R^{\text {wt }}$ and $p E F-\Delta T-h R^{R 477 H}$ using Superfect ${ }^{\mathrm{TM}}$ Transfection Reagent (Qiagen, Valencia, CA, USA) according to the manufacturer's instructions. Cells were either treated with $10^{-7} \mathrm{M}$ Dex for $24 \mathrm{~h}$, or carrier $(0.01 \%$ ethanol). Equal amounts of protein, quantified with a Bradford assay, were used for luciferase assays (Dual-Luciferase Reporter Assay System, Promega, Madison, WI, USA). Firefly luciferase levels, detected with a luminometer (Lumat ${ }^{\mathrm{TM}}$ LB9501, Berthold), were then normalized against co-expressed constitutive renilla luciferase levels.

\section{Transrepression assay}

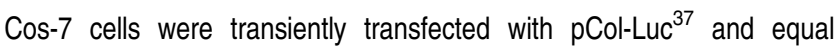
amounts of $\mathrm{pEF} \Delta \mathrm{T}-\mathrm{hGR}^{\mathrm{wt}}$ or $\mathrm{pEF} \Delta \mathrm{T}-\mathrm{hGR}^{\mathrm{R} 477 \mathrm{H}}$, and grown overnight in medium stripped with charcoal to remove endogenous steroids. Col-LuC was induced with $50 \mathrm{ng} / \mathrm{ml} \mathrm{TPA}$ and $4 \mu \mathrm{M}$ ionomycin for $8 \mathrm{~h}$ and repressed by the GR with $10^{-7} \mathrm{M}$ dexamethasone $1 \mathrm{~h}$ prior to Col-Luc induction. Bradford and luciferase assays were performed as described above.

\section{Whole-cell radioligand-binding assay}

As detailed previously, ${ }^{22} 5 \times 10^{6}$ cells were incubated with increasing amounts of ${ }^{3} \mathrm{H}$-triamcinolone acetonide in the presence or absence of competitor (unlabeled triamcinolone acetonide in excess) for $1 \mathrm{~h}$ at $37^{\circ} \mathrm{C}$. After three washes, pellets were resuspended in scintillation cocktail and counted in a scintillation counter.

\section{Determination of apoptosis}

Apoptosis was determined by propidium iodide staining of nuclei ${ }^{38}$ using a Beckton Dickinson FACS-Calibur as detailed previously. ${ }^{39}$ Briefly, cells were centrifuged and resuspended in a buffer $0.1 \%$ Triton X-100, $0.1 \%$ sodium-citrate and $0.005 \%$ propidium-iodide. Sub-G1 events in the fluorescence channel represent apoptotic nuclei.

\section{Generation of T-ALL cells retrovirally transduced with $\mathbf{G R}^{\mathbf{R} 47 \mathrm{H}}$}

Plasmid pLib-IGN is a pLIB-derived retroviral expression vector (Clontech, USA) containing an IRES-GFP-Neo expression cassette, ${ }^{40}$ and was kindly provided by Ralph Gräser (Institute of Tumor Biology, Freiburg, Germany). GR-coding sequences were amplified from $p E F-\Delta T-h R^{w t}$ and $p E F-\Delta T$ $\mathrm{hGR}^{\mathrm{R} 477 \mathrm{H}}$ with Pfu DNA-polymerase using the primers:

5'-TATACAATTGCCACCATGGACTCCAAAGAATCATTAAC-3' and 5'-TATAGCGGCCGCTCACTTTTGATGAAACAGAAG-3', digested with Munl and Notl, dephosphorylated with calf intestinal phosphatase and inserted into pLib-IGN, resulting in pLib-IGN-hGR ${ }^{\mathrm{wt}}$ and pLib-IGN$\mathrm{hGR}^{\mathrm{R} 477 \mathrm{H}}$, respectively. In all, $2 \mu \mathrm{g}$ of either one of these plasmids or a control lacking a GR insert were transfected into $1 \times 10^{6}$ Phoenix packaging cells together with $1 \mu \mathrm{g}$ of a plasmid coding for vesicular stomatitis virus protein VSV-G using $12 \mu \mathrm{l}$ Metafectene $^{\mathrm{TM}}$ (Biontex Laboratories $\mathrm{GmbH}$, Munich, Germany) according to the manufacturer's instructions. The retrovirus-containing supernatants were filtered through $0.45 \mu \mathrm{m}$ syringe filters (Sartorius, Göttingen, Germany) $48 \mathrm{~h}$ after transfection, and centrifuged onto $1 \times 10^{6} \mathrm{CEM}-\mathrm{C} 7 \mathrm{H} 2$ cells for $40 \mathrm{~min}$ at $700 \mathrm{~g}$ in a cell culture centrifuge. After $48 \mathrm{~h}$, the infected cells were 
subjected to a selection culture ( $1 \mathrm{mg} \mathrm{G} 418 / \mathrm{ml}$ ) for 10 days and subsequently used for experiments.

\section{Acknowledgements}

We thank Mag. Harald Niederegger and Mag. Christian Ploner for participation in confocal microscopy and retroviral transduction respectively, Drs. Arno Helmberg and Julian Gannon for providing cell lines, plasmids and antibodies, and M Kat Occhipinti for editing the manuscript. This work was supported by the Austrian Science Fund (SFB-F002, SFBF021, P14482-MOB), the Austrian Ministry of Education. Science and Culture (GEN-AU-CHILD) and the European Community (QLG1-CT-200101574 - 'EUGIA'). The Tyrolean Cancer Research Institute is supported by the 'Tiroler Landeskrankenanstalten Ges.m.b.H. (TILAK)', the 'Tyrolean Cancer Society', various businesses, financial institutions and the People of Tyrol.

\section{References}

1. Pui C-H (1995) Childhood leukemias. N. Engl. J. Med. 332: 1618-1630

2. Whittacker JA and Holmes JA (1998) Leukaemia and Related Disorders, 3rd ed. (Oxford: Blackwell Science Ltd)

3. Dordelmann M, Reiter A, Borkhardt A, Ludwig WD, Gotz N, Viehmann S, Gadner H, Riehm H and Schrappe M (1999) Prednisone response is the strongest predictor of treatment outcome in infant acute lymphoblastic leukemia. Blood 94: 1209-1217

4. Kofler R, Schmidt S, Kofler A and Ausserlechner MJ (2003) Resistance to glucocorticoid-induced apoptosis in lymphoblastic leukemia. J. Endocrinol. 178: 19-27

5. Gustafsson J-Å, Carlstedt-Duke J, Poellinger L, Okret S, Wikström A-C, Brönnegård M, Gillner M, Dong Y, Fuxe K, Cintra A, Härfstrand A and Agnati L (1987) Biochemistry, molecular biology, and physiology of the glucocorticoid receptor. Endocr. Rev. 8: 185-234

6. Laudet V and Gronemeyer H (2002) The Nuclear Receptor Facts Book. (London: Academic Press)

7. Geley S, Fiegl M, Hartmann BL and Kofler R (1996) Genes mediating glucocorticoid effects and mechanisms of their regulation. Rev. Physiol. Biochem. Pharmacol. 128: 1-97

8. Tonko M, Ausserlechner MJ, Bernhard D, Helmberg A and Kofler R (2001) Gene expression profiles of proliferating versus $\mathrm{G} 1 / \mathrm{G} 0$ arrested human leukemia cells suggest a mechanism for glucocorticoid-induced apoptosis. FASEB J. 15: 693-699

9. Planey SL, Abrams MT, Robertson NM and Litwack G (2003) Role of apical caspases and glucocorticoid-regulated genes in glucocorticoid-induced apoptosis of pre-B leukemic cells. Cancer Res. 63: 172-178

10. Wang Z, Malone MH, He H, McColl KS and Distelhorst CW (2003) Microarray analysis uncovers the induction of the pro-apoptotic $\mathrm{BH} 3$-only protein Bim in multiple models of glucocorticoid induced apoptosis. J. Biol. Chem. 278: 23861-23867

11. Beato M, Herrlich P and Schütz G (1995) Steroid hormone receptors: many actors in search of a plot. Cell 83: 851-857

12. Ausserlechner MJ, Obexer P, Böck G, Geley S and Kofler R (2003) Cyclin D3 and c-myc control glucocorticoid-induced cell cycle arrest but not apoptosis in lymphoblastic leukemia cells. Cell Death Differ. 11: 165-174

13. Hala M, Hartmann BL, Böck G, Geley S and Kofler R (1996) Glucocorticoid receptor gene defects and resistance to glucocorticoid-induced apoptosis in human leukemic cell lines. Int. J. Cancer 68: 663-668

14. Strasser-Wozak EMC, Hattmannstorfer R, Hála M, Hartmann BL, Fiegl M, Geley S and Kofler R (1995) Splice site mutation in the glucocorticoid receptor gene causes resistance to glucocorticoid-induced apoptosis in a human acute leukemic cell line. Cancer Res. 55: 348-353

15. Powers JH, Hillmann AG, Tang DC and Harmon JM (1993) Cloning and expression of mutant glucocorticoid receptors from glucocorticoid-sensitive and -resistant human leukemic cells. Cancer Res. 53: 4059-4065
16. Ashraf $J$ and Thompson EB (1993) Identification of the activation-labile gene: a single point mutation in the human glucocorticoid receptor presents as two distinct receptor phenotypes. Mol. Endocrinol. 7: 631-642

17. Antakly T, Thompson EB and O'Donnell D (1989) Demonstration of the intracellular location and up-regulation of glucocorticoid receptor by in situ hybridization and immunocytochemistry. Cancer Res. 49: 2230s-2234s

18. Ramdas J, Liu W and Harmon JM (1999) Glucocorticoid-induced cell death requires autoinduction of glucocorticoid receptor expression in human leukemic T cells. Cancer Res. 59: 1378-1385

19. Kofler R (2000) The molecular basis of glucocorticoid-induced apoptosis of lymphoblastic leukemia cells. Histochem. Cell Biol. 114: 1-7

20. Hillmann AG, Ramdas J, Multanen K, Norman MR and Harmon JM (2000) Glucocorticoid receptor gene mutations in leukemic cells acquired in vitro and in vivo. Cancer Res. 60: 2056-2062

21. Liu W, Hillmann AG and Harmon JM (1995) Hormone-independent repression of AP-1-inducible collagenase promoter activity by glucocorticoid receptors. Mol. Cell Biol. 15: 1005-1013

22. Geley S, Hartmann BL, Hala M, Strasser-Wozak EMC, Kapelari K and Kofler R (1996) Resistance to glucocorticoid-induced apoptosis in human T-cell acute lymphoblastic leukemia CEM-C1 cells is due to insufficient glucocorticoid receptor expression. Cancer Res. 56: 5033-5038

23. Helmberg A, Auphan N, Caelles C and Karin M (1995) Glucocorticoid-induced apoptosis of human leukemic cells is caused by the repressive function of the glucocorticoid receptor. EMBO J. 14: 452-460

24. Hollenberg SM, Weinberger C, Ong ES, Cerelli G, Oro A, Lebo R, Thompson EB, Rosenfeld MG and Evans RM (1985) Primary structure and expression of a functional human glucocorticoid receptor cDNA. Nature 318: 635-641

25. Koper JW, Stolk RP, De Lange P, Huizenga NATM, Molijn GJ, Pols HAP, Grobbee DE, Karl M, De Jong FH, Brinkmann AO and Lamberts SWJ (1997) Lack of association between five polymorphisms in the human glucocorticoid receptor gene and glucocorticoid resistance. Hum. Genet. 99: 663-668

26. Ruiz M, Lind U, Gafvels M, Eggertsen G, Carlstedt-Duke J, Nilsson L, Holtmann M, Stierna P, Wikstrom AC and Werner S (2001) Characterization of two novel mutations in the glucocorticoid receptor gene in patients with primary cortisol resistance. Clin. Endocrinol. (Oxf.) 55: 363-371

27. Danielsen M, Northrop JP and Ringold GM (1986) The mouse glucocorticoid receptor: mapping of functional domains by cloning, sequencing and expression of wild-type and mutant receptor proteins. EMBO J. 5: 2513-2522

28. Starr DB, Matsui W, Thomas JR and Yamamoto KR (1996) Intracellular receptors use a common mechanism to interpret signaling information at response elements. Genes Dev. 10: 1271-1283

29. Meyer T, Starr DB and Carlstedt-Duke J (1997) The rat glucocorticoid receptor mutant K461A differentiates between two different mechanisms of transrepression. J. Biol. Chem. 272: 21090-21095

30. Stockner T, Sterk H, Kaptein R and Bonvin AM (2003) Molecular dynamics studies of a molecular switch in the glucocorticoid receptor. J. Mol. Biol. 328: 325-334

31. D’Adamio F, Zollo O, Moraca R, Ayroldi E, Bruscoli S, Bartoli A, Cannarile L, Migliorati $G$ and Riccardi C (1997) A new dexamethasone-induced gene of the leucine zipper family protects T lymphocytes from TCR/CD3-activated cell death. Immunity 7: 803-812

32. Norman MR and Thompson EB (1977) Characterization of a glucocorticoidsensitive human lymphoid cell line. Cancer Res. 37: 3785-3791

33. Masters JR, Thomson JA, Daly-Burns B, Reid YA, Dirks WG, Packer P, Toji LH, Ohno T, Tanabe H, Arlett CF, Kelland LR, Harrison M, Virmani A, Ward TH, Ayres KL and Debenham PG (2001) Short tandem repeat profiling provides an international reference standard for human cell lines. Proc. Natl. Acad. Sci. USA 98: 8012-8017

34. Nagai T, Ibata K, Park ES, Kubota M, Mikoshiba K and Miyawaki A (2002) A variant of yellow fluorescent protein with fast and efficient maturation for cellbiological applications. Nat. Biotechnol. 20: 87-90

35. Pepperkok R, Squire A, Geley S and Bastiaens PI (1999) Simultaneous detection of multiple green fluorescent proteins in live cells by fluorescence lifetime imaging microscopy. Curr. Biol. 9: 269-272

36. Doppler W, Windegger M, Soratroi C, Tomasi J, Lechner J, Rusconi S, Cato AC, Almlof T, Liden J, Okret S, Gustafsson JA, Richard-Foy H, Starr DB, Klocker H, Edwards D and Geymayer S (2001) Expression level-dependent 
contribution of glucocorticoid receptor domains for functional interaction with stat5. Mol. Cell. Biol. 21: 3266-3279

37. Deng T and Karin M (1993) JunB differs from C-Jun in its DNA-binding and dimerization domains, and represses c-Jun by formation of inactive heterodimers. Genes Dev. 7: 479-490

38. Nicoletti I, Migliorati G, Pagliacci MC, Grignani F and Riccardi C (1991) A rapid and simple method for measuring thymocyte apoptosis by propidium iodide staining and flow cytometry. J. Immunol. Methods 139: 271-279
39. Geley S, Hartmann BL, Hattmannstorfer R, Löffler M, Ausserlechner MJ, Bernhard D, Sgonc R, Strasser-Wozak EMC, Ebner M, Auer B and Kofler R (1997) P53-induced apoptosis in the human T-ALL cell line CCRF-CEM. Oncogene 15: 2429-2437

40. Geley S, Kramer E, Gieffers C, Gannon J, Peters JM and Hunt T (2001) Anaphase-promoting complex/cyclosome-dependent proteolysis of human Cyclin A starts at the beginning of mitosis and is not subject to the spindle assembly checkpoint. J. Cell Biol. 153: 137-148 